\title{
Problems of formation of civic identity of students' personalities in modern conditions of development of Russian education and society
}

\author{
Tatyana Bespalova* \\ Ryazan State University, 390000 Ryazan, Russia
}

\begin{abstract}
The article presents a theoretical analysis of the problem of civic identity in the conditions of intensive development of modern social relations and the educational environment. The relevance of the study of the civic identity of a person during youth, when the formation of the selfconcept is of particular importance, is described. The author's methodology was used. The study led to the conclusion that in youth civic identity, being the central component of the "I-concept" of the individual, plays the role of a social glue that holds together the details of the social mechanism, providing a contextual structure of identity. It is shown that the majority of students are distinguished by an average level of status severity: because of personal immaturity young people do not form the semantic content of the concept of an active citizenship, that impedes the constructive overcoming of the crisis and the development of a civic identity. Correlation analysis, revealed the connection between the components of the structure of the civic identity and status, indicates the need for harmonization of the personality of young people by increasing reflection, independence, leading to the development of an internal locus of control and citizenship.
\end{abstract}

\section{Introduction}

In youth a person undergoes significant changes in his development, due to the struggle of motives when entering an independent life. During this period of ontogenesis, the realization of the personal potential laid down in the process of upbringing and rooted in consciousness by the social way of life is especially important. It is the formation of the self-concept, the meaning of life orientations, moral attitudes and principles that are able to form the inner position of the young man, when turning to the future becomes the orientation of the personality; the vector of development of the further life path, selfdetermination, gaining one's civic identity, turning into the center of a life situation around which all activity begins to revolve. In recent years, the younger generation has been actively involved in the process of transforming the educational space that has embarked on the rails of modernization and globalization. New requirements for participants in the educational environment are both challenges and incentives for the development of the

\footnotetext{
* Corresponding author: barbos070276@yandex.ru
} 
personality of a young person. Integrating into the system of subject-subject relations, providing not only the acquisition of new knowledge, skills, but also internalization through the prism of an individual substrate of the psyche - cultural heritage a person forms a picture of the world, learns to manifest his self.

At the same time, education, according to AbakumovaI.V., has a prolonged meaning, in which not only the process of a person entering the image of the I and the Ego is carried out, but also it becomes necessary "a person to go beyond his own actual" I "within his basic, potential "I". "This, accordingtotheauthor, isnothingmorethandevelopment, a newconditionforlife" [1, p.21].

Modification of the education system, the transition to new federal state educational standards, providing for a competency-based approach, and taking into account the adopted professional standards when implementing the main educational program, require a young man with flexibility of mind, sociability, initiative and responsibility - all that characterizes a person as an active person and citizen. Society and educational space are targeting young people to manifest general erudition, substantive abilities, and a strong consolidating civic position.

Based on our concept and the author's model built on its basis, we understand civic identity as an awareness of belonging to the state that has significant personal meaning. The civic identity of a person includes components determined by individual properties (primarily temperament), such as civic identity, moral attitudes, social distance, subjectivity. According to our model, each component includes psychological variables. So, the component of civic identity includes self-esteem, self-referentiality and self-awareness; a component of a moral attitude - patriotism, "the image of the Motherland" (integral indicator); a component of social distance is national self-determination, language acceptance and tolerance; component of subjectivity - responsibility, internality, activity. In our opinion, civic identity, being a dynamic structure that develops throughout the entire life path of a person, is formed as a result of the process of self-identification of the subject with the community and is manifested in value-motivational, cognitive, emotional and behavioral aspects. At the same time, the civic identity of a person is most clearly reflected in the value-semantic aspect through the prism of acceptance (appropriation) of the values of civil society; in the cognitive - through reflexivity, criticality, flexibility of thinking, meaningfulness / awareness; emotionally, through an evaluative attitude to the process of forming a civic position and the current status of civic identity; in dynamic (behavioral) through sovereignty, behavioral activity and communicative effectiveness. The set of determinants (variables) expressing the formation of the individual ensures the integrity of each component. In turn, the unity of the components determines the formation of the civic identity of the person, which can be determined by the measure of responsibility and the level of its development, the nature of the severity of the self-concept, motivational readiness for personal growth. The initiation of a civic identity of a person depends on the upbringing in the personality of a citizen endowed with civic self-awareness and selfidentification.

\section{The relevance of research}

Nowadays the problem of civic education and training, due to its relevance and the need to find solutions, is in the plane of studying many humanitarian disciplines. At the same time, the development of a sense of civic identity among the young generation requires further careful study, since one of the priority tasks of modern education is the formation of the youth's ability to relate to civil society, its moral and legal norms and values. This will allow young people to recognize themselves as full citizens of their country, to feel that they belong to a particular civic community and sociocultural group, and will ensure the 
development of human citizenship and the desire to work for the good of the state and society.

The study of civic identity as a phenomenon in the scientific environment is carried out, as a rule, in the plane of combined disciplines and branches of scientific knowledge. Drobizheva L.M. notes the multidimensionality of civic identity [2], and Dyakova V.V. emphasizes that the category of identity at the present stage of development of domestic science is interdisciplinary in nature [3]. Studying identity in both a broad and subject context, scientists rely, as a rule, on the work of Erickson E., who understood identity as "self-identification", which has a socio-cultural basis, and drew attention to its connection with ideology [4]. Moreover, most often the basis for building the ideology of research among scientists is the concept of Mead D. on the formation of identity in the process of interaction with others [5] and the postulate of Marcelo K., Lopez M. that the individual acquires his identity in the process of communication with a social group [6].

In the domestic scientific literature, the process of the formation of a civic identity of the person in the last two decades has been reasonably given great attention, since the mechanisms of formation of an active civic position predetermine the essence of the person, which can become the driver of the development of a modern democratic state and society.

In his works Nikovskaya N.I. defines the process of forming a civic identity of an individual as the most important factor in the unification of Russian society, which, according to the author, is interested in building an identity that contributes to the favorable social well-being of citizens, their solidarity and cohesion as resources for social development [7]. The civic identity of subjects of various types of activities is considered in the works of Shikova R.Y., Grishina E.A., Akhmetshina G.K., Loginova A.A. [8, 9, 10,11]. Research of Harutyunyan Y.V., Semenenko I.S. devoted to the issues of the formation of civic identity under the influence of globalization $[12,13]$. Wherein Sanina A.G. believes that subjective feelings of identity, due to previous traditions, under the conditions of modern processes of globalization and transformation are subject to profound changes [14]. In their studies, Pavlenko V.N., Korzh N.N. emphasize that civic identity is associated with the transformation of a person's ideas about his place in the social environment under the influence of social change [15]. Yaroslavskaya O.K. notes that human activity, his consciousness, initiative are the basis of civil society, which, in turn, forms the independence, subjectivity, autonomy of a citizen [16]. Citizenship, according to Knyazev A.M., is the social competence of a person [17].

Thus, we, in agreement with the opinion of Malinova O. Y., believe that the analysis of identity markers that support the space of human life and development is of particular importance for modern psychological research [18]. It should be noted that the study of civic identity is primarily sociological and political in nature. All this determines the relevance of the problems of studying the issues of the formation of the civic identity of a person, its psychological structure. The task of the formation of this psychological phenomenon during youth acquires special sound in connection with the rapidly changing conditions of training, development, and vital activity of the young generation.

Our study of civic identity is carried out in the framework of the author's psychological model using the author's method of diagnosing the formation of the status of civic identity achieved, moratorium, pseudo-identity, imposed, diffusedd. Note that under the model, we, like Gulina M.A., Zinchenko Y.P., mean "symbolic representation of the perceived phenomenon" $[19$, p. 24]. In this case, the phenomenon of civic identity of a person fits into the framework of a psychological construct, which, according to Zinchenko Y.P., is endowed with a conceptual meaning that defines a higher level of abstractness [19, p. 25].

Statuses determine the severity of the above components - civic identity, moral attitudes, social distance, subjectivity. The result is not just a determination of the degree of expression of the components, but also a diagnosis of the level of formation of the status of 
the civic identity of the person. Such a multidimensional approach makes it possible to see the psychological structure of the civic identity of a person, anticipate the further development of personality properties that ensure its formation, and also develop recommendations for its harmonization.

\section{Methods and techniques}

The methodology includes 4 scales for the names of the components (civic identity, moral attitude, social distance and subjectivity). Moreover, each of the scales contains several variables that determine its semantic content. The fifth scale is generalizing and reflects the civic identity of the person. In all scales, the formation of statuses is determined - achieved, moratorium, pseudo-identity, imposed, diffused identity. Thus, the greater severity of any status of a generalized - fifth - scale indicates how consciously and actively a person shows his civic position in various fields of activity; the severity of any status of the remaining four scales demonstrates the formation in one way or another of one of the spheres of personality.

The study was conducted among 386 students of the humanitarian and technical profiles of S.A. Yesenin. The level of status formation was calculated using the statistical standard deviation method (standard deviation - sigma); to determine the normality of the distribution, the non-parametric Z-Kolmogorov-Smirnov criterion was used; To identify the relationship between the statuses of the various components of the civic identity, the rPearson correlation coefficient was used.

\section{The discussion of the results}

A generalized indicator of civic identity demonstrates the variability of the distribution of statuses. So, no more than $10 \%$ of students have a high level of status "achieved identity"; "Moratorium" - 18\%; "Pseudo-identity" - 25\%; "Imposed" - 10\%; "Diffused" - 24\%. The same number of young people represents the bipolar orientation of the individual: some have reached a deep understanding of the need to show their activity and potential for the benefit of the development of society and the state, others, on the contrary, show infantility in the choice of life strategy and goal-setting, differ in their suspicion and conformity, and focus solely on the opinion of significant people; Some students, for the sake of public recognition, demonstrate pseudo-patriotism, pseudo-citizenship due to the lack of moral guidelines, another part - cynical indifference and detachment to the life of the state and society, often confronting and boycotting external processes and challenges . A fifth of the young people surveyed did not decide on the semantics of "good" and "evil", therefore, being in the establishment of causal social relations and relationships, they are in a state of personal self-determination and the search for the meaning of life.

The components of the structure of the civic identity of the person, the synthesis of which determines the above-described generalized indicator, are also expressed by different formation of statuses. It can be stated that most young people have an average level of status: "achieved identity", "moratorium", "pseudo-identity", "imposed", "diffused", which indicates their lack of formalization of moral, moral and value-semantic spheres of personality that allow them to feel yourself a full member of society and realize an active citizenship. Only a few of them fully feel the readiness to bear responsibility for themselves, their future and the future of their country. For the most part, young people are experiencing an identity crisis, a constructive way out of which can become an incentive for personal development, understanding and the formation of their civic position. In addition, low reflexivity, self-criticism, rigidity of self-concept often inhibit the development of 
internal potential. However, overcoming the fear of the difficulties of personal development can increase independence, stimulate emotional, moral and intellectual development. All this will contribute to increasing the motivation of achievements, developing adequate selfesteem, changing attitudes towards oneself, including gaining confidence in one's abilities, satisfaction with one's abilities, knowledge, skills.

The correlation analysis revealed the relationship between the statuses of the various components of the civic identity of students' personalities (correlation coefficient with significance level / $\mathrm{p} /=0.01$ ). The statuses of the generalized indicator of civic identity of a person have the following negative connections with the statuses of the component "Civil Identity": the achieved identity is associated with diffused identity $(r=-0.520)$; moratorium - with achieved identity $(\mathrm{r}=-0.442)$, pseudo-identity $(\mathrm{r}=-0.492)$, imposed identity $(\mathrm{r}=$ $0.500)$; pseudo-identity - with a moratorium $(\mathrm{r}=-0.568)$ and diffused identity $(\mathrm{r}=-0.520)$; imposed identity - with a moratorium $(r=-0.600)$; diffused identity - with the achieved $(r=$ $-0.524)$.

Correlation relationships between the statuses of the components "Moral and moral attitudes", "Civil identity" and the statuses of the general indicator of civic identity are presented as follows. The correlation core is the status of the diffused identity of the component "Moral attitudes." It is negatively related to the achieved $(r=-0.618)$ and pseudo-identity $(\mathrm{r}=-0.669)$ of the same component, as well as negatively to the achieved $(\mathrm{r}=-0.461)$, pseudo-identity $(\mathrm{r}=-0.634)$, imposed identity $(\mathrm{r}=-0.300)$ and positively with diffused identity $(\mathrm{r}=0.767)$ of a generalized indicator of civic identity. In addition, diffused identity is associated positively with diffused identity $(\mathrm{r}=0.489)$, negatively with the achieved $(r=-0.365)$ and pseudo-identity $(r=-0.175)$ component of "Civil Identity".

Correlations between the statuses of the components "Social distance", "Moral attitudes", "Civil identity" and the statuses of the general indicator of civic identity are presented as follows. The correlation core is the status of the achieved identity of the Social Distance component, which has 11 connections - 3 positive and 8 negative. 3 positive relationships were found with the achieved identity $(\mathrm{r}=0.633)$ of the general indicator of civic identity of the individual and the Moral Attitudes component $(\mathrm{r}=0.202)$, as well as with the pseudo-identity $(\mathrm{r}=0.400)$ of the Moral Attitudes component. 8 negative connections were found with a moratorium $(r=-0.298)$, imposed $(r=0.282)$, diffused $(r=$ $0.436)$ identity of the Social Distance component; a moratorium $(r=0.166)$, imposed $(r=$ $0.230)$ and diffused identity $(\mathrm{r}=0.322)$ of the general indicator of civic identity; diffused $(\mathrm{r}$ $=0.436)$ and imposed identity $(\mathrm{r}=0.333)$ of the component "Social distance". The correlation relationships established indicate that the status of a diffused identity can develop if there is no clear understanding of one's civic position, place and time of its implementation. The status of a moratorium can be expressed if there is an active search for one's self, including when leaving the zone of psychological comfort, the desire to know the inner world and, on the basis of newly acquired personal experience, to make independent, non-imposed choices is heightened. The status of pseudo-identity can be reduced due to the harmonization of personality, leveling of such contradictory states as the desire for an active life choice, on the one hand, and dependence on the opinions of significant individuals, on the other. The resolution of this dilemma will make it possible to overcome the rigidity of thinking, reduce demonstrativeness and hyperidentity, and abandon declarativeness. The loss of the status of an imposed identity is possible by increasing the desire for self-reliance and, as a consequence, a change in life scenario.

\section{Conclusion}

Thus, the study showed that the personality ofyouth undergoes significant changes in its formation and development, due to the struggle of motives when entering an independent 
life. Students who are mainly focused on momentary desires do not show the ability to build life plans and prospects, set goals and form attitudes and values. Changing their life position to a more active one will entail the unconditional dynamics of the development of a civil position that meets the realities of the present in the context of the prospects for increasing the educational function of the individual and the requirements of modern Russian society and the rule of law.

\section{References}

1. I.V. Abakumova, General theory of meaning, psychological concepts of meaning formation, meaning didactics. Reader (CREDO,Moscow,2014)

2. L.M. Drobizheva, Social problems of interethnic relations in post-Soviet Russia(Center for Human Values, Moscow, 2003)

3. V.V. Dyakova, Civil identity of generations in modern Russia: a sociological analysis.The dissertation of a candidate of sociological sciences(Astrakhan, 2017)

4. E.H. Erikson, The Life Cycle Completed (W.W. NortonCompany,New York City, 1982)

5. G. H. Mead, Mind, self, and society: from the Standpoint of a social behaviorist(The University of Chicago Press, Chicago, 1992)

6. K. Marcelo, M. Lopez, E. Kirby, Civic engagement among young men and women(CIRCLE, USA, 2007)

7. L.I. Nikovskaya, State Administration of the Russian Federation: Challenges and Prospects, Proceedings of the 15th International Conference Public Administration in the 21st Century: Compilation, Electronic Edition of Network Distribution. 646-650 (2018)

8. R.Y. Shikova, Bulletin of the Adygea State University, Series 1: Regional studies: philosophy, history, sociology, jurisprudence, political science, cultural science. No. 1. 111116(2009)

9. E.A. Grishina, Civil Identity of Russian Youth: the Experience of Monitoring Studies of the 90s. The dissertation of a doctor of sociological sciences(Moscow, 2002)

10. G.K.Akhmetshina, Patriotic education as a factor in the formation of civic identity of students. The dissertation of the candidate of pedagogical sciences(Kazan, 2015)

11. A.A. Loginova, Formation of civic identity of schoolchildren by means of Internet resources. The dissertation of the candidate of pedagogical sciences(Samara, 2010)

12. Y.V. Harutyunyan, Social sciences and modernity, T. 4 - Social sciences and modernity, 91-97 (2009)

13. E.S. Semenenko, Political Identity and Identity Policy, T.1 .. Identity as a category of political science: a dictionary of terms and concepts (ROSSPEN, Moscow, 2012)

14. A.G. Sanina, The Formation of Russian Identity(MAX-Press, Moscow, 2013)

15. V.N. Pavlenko, N.N. Korzh, Psychological journal, T.19. No. 1, 53-62 (1998)

16. O.K. Yaroslavskaya, Problems of civil and regional identity in modern Russia, Problems of civil and regional identity in modern Russia: a collection of scientific papers. $32(2015)$

17. A.M. Knyazev, Acmeological and pedagogical concept of civic education in the system of Russian education. The dissertation of a doctor of pedagogical sciences (Moscow, 2008)

18. O.Y. Malinova, Russia and the "West" in the 20th Century: Transformation of the Discourse on Collective Identity(ROSSPEN, Moscow, 2009)

19. M.A. Gulina, Y.P. Zinchenko, Advisory Psychology.Series: Textbook for high schools. Third Generation Standard (Publisher Peter, St. Petersburg ,2018) 